\title{
Marguerite Yourcenar: del destierro espacial al destierro interior
}

\author{
Jean-Pierre CASTELLANI \\ Universidad François Rabelais de Tours \\ jpcastellani@wanadoo.fr
}

\section{RESUMEN}

Marguerite Yourcenar nació en Europa (1903) pero pasó la mayor parte de su vida en Estados Unidos (1939-2007). ¿Esta estancia fuera, a raíz de la Segunda Guerra Mundial, basta para considerarla como una desterrada en el sentido estricto de la palabra? Creemos que puede ser significativo estudiar los motivos de la decisión tomada por la joven autora, en 1939, de vivir en otra tierra distinta a la de sus orígenes, el norte de Francia y Bélgica, y de permanecer allí hasta su muerte, para entender su afición por los viajes, su nomadismo y su cosmopolitismo. El examen de su obra El denario del sueño nos ayudará a plantear este tema.

Palabras clave: destierro, viaje, espacio, isla, lengua.

Marguerite Yourcenar: from spatial to interior banishment

\begin{abstract}
Marguerite Yourcenar was born in Europe (1903) but spent most of her life in the United States (1939-2007). Is this living abroad, because of the Second World War, enough to consider her a banished person in the strict sense of the word? It might be significant to study the motives of the decision taken by the young author, in 1939, of living in a land other than her origins, the north of France and Belgium, and remain there until her death, to understand her love of travel, her nomadism and her cosmopolitism. An exam of her book Denier du rêve will help us propose this issue.
\end{abstract}

Key words: banishment, travel, space, island, language.

La imagen que solemos tener de Marguerite Yourcenar es la de una escritora académica en el doble sentido de la palabra: por una parte equilibrada, distanciada, medida, moderada, dueña de su destino, segura de su cuerpo y de sus pasiones, 
imponiéndose a todo el mundo: editores, lectores, crítica literaria, amigos, y por otra, reconocida como la primera mujer en ser elegida miembro de la Academia francesa en 1980, y recibida en 1981.

Sin embargo, las tres biografías publicadas hasta hoy han revelado parte de esos secretos muy vigilados y controlados por la propia Yourcenar en vida, y destacan un desdoblamiento permanente entre la figura pública y la verdadera y auténtica personalidad de una mujer más compleja de lo que parece, que siempre se negó a las confidencias personales. Los títulos de esas biografías: Yourcenar, l'invention d'une vie (Savigneau 1990), Vous, Yourcenar. La passion et ses masques (Sarde 1995) y Yourcenar, biographie, "Qu'il eût été fade d'être heureux" (Groslar 1998), escritas todas después de la muerte de la escritora en 1987 y por mujeres, o sea con una libertad de tono completa y fuera del control de la misma Yourcenar, reflejan perfectamente esas ambigüedades.

Pero hay un tema que Yourcenar trató con cierta franqueza y sinceridad, es el de su situación en Estados Unidos, las condiciones de su estancia y los motivos por los cuales se quedó fuera de Europa durante tantos años.

Para empezar, hay que plantear un postulado: el gusto de Yourcenar por los viajes; y para entender sus relaciones con el viaje, el testimonio del periodista Christian Dumais-Lvowisky nos informa particularmente. En su libro La promesse du seuil, un voyage avec Marguerite Yourcenar (2002) cuenta algunos de sus encuentros con Yourcenar: en París (diciembre de 1986), la estancia en Marruecos con la escritora y su amigo fotógrafo Saddri Derradji (febrero de 1987) y el encuentro en su casa de Petite Plaisance en agosto de 1987, en la isla americana de Mount-Desert. A lo largo de esas conversaciones libres y espontáneas, Yourcenar le explica largo y tendido cómo y por qué quiere volver a los lugares y paisajes que conoció y recorrió con los seres amados, en este caso con Jerry Wilson, su último compañero sentimental con el cual viajó a Egipto y Marruecos en 1982 y a Japón, Tailandia y Grecia en 1983. En el programa de ese largo viaje previsto para diciembre de 1987, Yourcenar tenía el proyecto de regresar a Ámsterdam, Copenhague, Munich, Zúrich, París y luego emprender un recorrido por la India, el Nepal y, por fin, el Tíbet, donde deseaba entrevistarse con el dalaï-lama. Este viaje se había anulado después de la muerte de Jerry Wilson en febrero de 1986. Sabemos sin embargo que Yourcenar no abandonó este proyecto y que, hasta los últimos meses de su vida, continuó escribiendo cartas a amigos suyos para que la acompañaran en su periplo, en compañía de su enfermera neerlandesa Janet Hartielf ${ }^{1}$.

\footnotetext{
${ }^{1}$ Es lo que se puede leer en las cartas que cruza con un joven italiano llamado Paulo Zacchera, especialista en floricultura, con el cual se corresponde Yourcenar, entre 1979 y 1987, sobre todo después de la muerte de Jerry Wilson, en febrero de 1986. Entonces el epistolario se vuelve más regular e íntimo y tiene como tema principal la organización puntillosa del viaje a La India. Yourcenar explica, en sus cartas a su joven correspondiente, que desea volver a los lugares donde conoció la felicidad con Jerry Wilson. Es asombroso descubrir con qué entusiasmo y con qué precisión discute, negocia e impone las condiciones prácticas de un viaje tan complicado, teniendo en cuenta que se trata de una mujer debilitada físicamente por el accidente sufrido en Nairobi en diciembre de 1983, y moralmente por la desaparición de los seres más queridos. He aquí lo que escribe a Zacchera, unos meses antes de su muerte: "Jusqu'à quel moment pourrez-vous rester dans l'Inde ? Je compte n'en rentrer que le $1^{\mathrm{e}}$ Mars au plus tôt [...]. Prière de me répondre le plus rapidement possible, car j'aurai à prendre des décisions à partir de là" (Zacchera 2009: 130-176).
} 
Desgraciadamente, el derrame cerebral que sufrió Yourcenar en noviembre de 1987 la obligó a aplazar indefinidamente ese viaje, y murió en el hospital de Bar Harbor en diciembre del mismo año.

Viajar vuelve inteligente, decía Albert Camus. Como un eco, Yourcenar confiesa a Christian Dumais-Lvowiski: "Apprendre dans les voyages et en dehors des voyages, est une grande raison d'être. Je me considère comme une perpétuelle étudiante dans toutes les conditions de la vie" (Dumais-Lvowski 2002: 28).

A este respecto, puede ser interesante, incluso útil y significativo cuestionar las relaciones íntimas de Yourcenar con el destierro para medir mejor su concepto del viaje. En una segunda parte estudiaremos, por motivos que explicaremos más adelante, el texto de Yourcenar El denario del sueño, que representa muy bien el tema.

Sin embargo, un examen más detallado del asunto nos va a llevar a una contestación más matizada, por lo ambiguo de la actitud de la autora y la compleja representación literaria a través de algunos de sus personajes.

Por lo demás, por motivos circunstanciales aparentemente independientes de su voluntad, Yourcenar pasó gran parte de su existencia en lo que se puede llamar un destierro. En efecto, el destierro, que es una forma de viaje obligado, está en el corazón de la creación literaria desde siempre, ya que el escritor, sobre todo la gran figura, se caracteriza por un cuidado, una obsesión de libertad que condujo a numerosos creadores a cortar con su época y, por consiguiente, a establecer relaciones conflictivas con la Historia, es decir, forzosamente con los poderes políticos dominantes. En la mayoría de los casos están asociadas estrechamente las condiciones individuales, culturales e históricas relacionadas con el alejamiento obligado de su tierra y con un fenómeno de sobrevivencia delicada que, a menudo, no se resuelve más que con el acto de escribir en el idioma del país perdido.

Observemos que Yourcenar, contrariamente a otros escritores, no abandonó nunca la lengua francesa como lengua de escritura, a pesar de haber vivido más tiempo fuera de Francia que en Francia y de compartir la vida de una americana o de amigos extranjeros, en un baño lingüístico esencialmente anglosajón.

Yourcenar vivió siempre en una especie de burbuja: careció de madre casi desde su nacimiento y, por lo tanto, no tiene lengua materna; al contrario, recibió lo que se puede llamar curiosamente una lengua paterna, el francés en este caso, al estar en contacto con su padre Michel, sin conocer una educación escolar. Yourcenar no conoció nunca la lengua familiar de la escuela, de los patios y de los compañeros de clase.

Su idioma es pues el que le inculcó un padre culto, el que aprendió y apreció a lo largo de las numerosas lecturas que hizo de niña y adolescente, y la de unos criados o familiares que la rodeaban y la cuidaban durante los primeros años que pasó en el Mont-Noir.

Forjó su lengua de escritora con esa base académica algo fija o rígida, aislada de la calle. En ningún momento tuvo la tentación de escribir en esa lengua inglesa con la cual, sin embargo, estuvo en contacto durante la mayor parte de su vida.

En su casa de Petite Plaisance, en Mount-Desert Island, tambien vivió en una burbuja lingüística francesa que prolongaba la que había conocido en Europa, pero que no era en absoluto fruto o manifestación de una nostalgia de desterrada. En defi- 
nitiva, ¿fue verdaderamente una desterrada Yourcenar? Para contestar a esta pregunta examinemos primero las relaciones entre la biografía de Yourcenar y las características fundamentales del estatuto tradicional del escritor desterrado.

Empecemos por unos datos cronológicos objetivos: Yourcenar nació en Bruselas en 1903, y vivió en Europa casi de modo continuo hasta 1939, fecha en la cual estalló la Segunda Guerra Mundial y ella salió para Estados Unidos, territorio en el cual va a residir hasta su muerte en 1987.

Se destierra, pues, aparentemente a los 36 años y pasa 47 años en una tierra lejana. Cuando da esta nueva orientación a su vida, sólo ha publicado unos libros²; escribirá y publicará los demás, los más importantes, a lo largo de lo que se puede llamar un largo destierro, espacial por lo menos.

La imagen que daba cuando vivía y que deja para la posteridad es la de una señora retirada en su isla americana muy lejana, con un nombre predestinado, la isla de los Montes Desiertos, en el Estado de Maine, frente al Canadá.

Esa hija de un aristócrata francés y de una señora de la nobleza belga no tuvo más que raíces culturales. A propósito de los lugares de su infancia que suelen ser los que construyen a un individuo, dice, hablando de las playas de Scheveningue en Holanda, o de Bélgica: "Je ne puis donc pas parler d'une enfance enracinée" (Yourcenar 1980: 17).

Estamos frente a una flamenca que no hace caso de sus orígenes ni de la genealogía en el sentido nacional del término, si bien se interesó por esas raíces más tarde, al reconstituir la historia de su familia. Nada la incitó a quedarse en el Mont-Noir, tampoco se aficionó a ningún espacio de su adolescencia ni se instaló en París o Bruselas ni en otro lugar de Europa.

Tal como su padre, aristócrata bohemio, es decir, errante, se dejó llevar siempre por la casualidad. Reivindica a este respecto: "Mais peut-être me serais-je développée de même si je vivais ailleurs. Qui sait, pourtant ? J'ai beaucoup de respect pour le hasard. Je crois à cette acceptation des objets donnés, et de la vie donnée, qu'il faut prendre telle qu'elle vient" (Yourcenar 1980: 138). Y hablando de la casa de su isla americana dice: "Donner le sentiment que c'est une halte au bord de la route. Je n'aime pas l'idée d'être trop encombrée de possessions. On en garde toujours trop" (Yourcenar 1980: 140).

Su existencia entera, desde la infancia y los años vividos al lado de su padre, en Europa primero y luego sola por el mundo entero, no fue más que una alternancia de viajes, de errancias incluso voluntarias, organizadas, programadas, a medida de sus descubrimientos, de sus pasiones estéticas, intelectuales o afectivas.

2 Estos libros son: Alexis ou le Traité du Vain Combat (1929), La Nouvelle Eurydice (1931), Maléfice (1933), Denier du rêve (primera versión, 1934), La mort conduit l'attelage (1934), Feux (1936), Nouvelles orientales (1938), Le Coup de grâce (1939). A estos libros hay que añadir unos ensayos, Pindare (1932), Les Songes et les Sorts (1938). Y unos libros de poesía como Le jardin des Chimères (1921) o Les Dieux ne sont pas morts (1922) fimados Marg YOURCENAR, nombre que conservará hasta la publicación de Alexis ou le Traité du Vain Combat. Adoptará el seudónimo de Marguerite Yourcenar a partir de 1931. Señalemos también una traducción: Virginia Woolf, Les vagues (The Waves) en 1931. 
El mismo nacimiento en Bruselas es una casualidad, se produce durante una residencia temporal de sus padres en esa ciudad. A partir de 1912, la instalación de su padre en París no los establece necesariamente en Francia, ya que no dejarán de viajar a través de Europa. En esa serie de etapas, siempre repetidas, encuentra a desterrados, experiencia desde la cual escribirá su novela Denier du rêve (El denario del sueño), pero en ningún momento se considera a sí misma como una persona separada de su tierra de origen. Por ejemplo, en 1914, la guerra les obliga a su padre y a ella a instalarse en Richmond, en Inglaterra, donde vio por cierto por primera vez, en el British Museum de Londres, el busto del emperador Adriano que iba a marcarla durante toda su vida. También en 1937 pasó los meses invernales en New Haven, en el estado de Connecticut, en Estados Unidos, con Grace Frick, a la que acababa de conocer. Pero son estancias cortas que no tienen nada que ver con la decisión existencial de un destierro.

Es cierto que en 1939 aparece, por primera vez, lo que se asemeja a un destierro: la salida definitiva hacia Estados Unidos y la instalación en esa isla de los Montes Desiertos que será su única residencia fija hasta su desaparición. Se puede decir, pues, que la declaración de guerra la sorprende cuando se dedicaba a sus viajes acostumbrados: el año nuevo en Tyrol, la estancia en Atenas y la decisión de pasar el invierno en Estados Unidos al lado de su nueva amiga Grace Frick, conocida a raíz de la primera estancia en New Haven.

Rompamos pues un relato ideal: cuando Yourcenar sube al barco en Burdeos en 1939 se produce tanto una huida de la Europa en guerra como la aplicación minuciosa de su programa personal de viajes, según su costumbre. Estamos, en este caso, en plena ambigüedad yourcenariana: huye del nazismo triunfante al que condena tajantemente desde el principio, pero al mismo tiempo emprende un periplo más, en un itinerario siempre nutrido de viajes.

Digamos que escoge la libertad política mientras que antes había manifestado su gusto por la libertad sexual. América se vuelve, de este modo, un refugio, después de haber sido una meta o, mejor dicho, un destino entre otros en su existencia de nómada libre.

Yourcenar ha sido interrogada a menudo a propósito de su estado de ánimo por esos años. Se percibe por una parte una ruptura en la que era su obsesión desde los veinte años: llegar a ser una escritora famosa y construir una obra coherente, ambiciosa y original. Confiesa sobre este particular: "J'avais quitté l'Europe, j'avais plus ou moins abandonné mon métier d'écrivain [...]. C'était comme une œuvre au noir, où tout se défait " (Yourcenar 1980: 131). Y añade:

De nombreux français, vivant en France, n'ont connu eux-mêmes les camps de concentration qu'en 1945, quand les gens sont revenus. C'était la même chose pour nous, exilés. Nous ne nous rendions pas compte, ou en partie seulement, de ce qui se produisait en Europe. Et quand on s'en rendait compte, c'était une sorte de choc individuel. (Yourcenar 1980: 133)

Es uno de los pocos ejemplos del uso de la palabra "exiliado" en el discurso de Yourcenar, sea en sus numerosas manifestaciones públicas, sea en sus escritos direc- 
tos o a través de personajes ficticios. Suele preferir el término más impreciso, y a la vez menos reductor de "frontera". Para resumir o sintetizar lo que experimentaba en esas tierras lejanas afirma:

Et puis la mer aère, tout de même. On a le sentiment d'être sur une frontière, entre l'univers et le monde humain. On demeure longtemps des étrangers, des nouveaux venus dans ces parages américains. En somme, c'est un paysage qui n'accepte pas très bien l'homme. (Yourcenar 1980: 134)

Va a desarrollar a lo largo de su vida el concepto de "cárcel" para caracterizar al universo, como afirma en el título de su obra Le Tour de la prison (Yourcenar 1991), una cárcel a la cual hay que dar la vuelta en viajes incesantes, curiosos y atentos como los que emprenden sus personajes Adriano, Zenon o Eric von Lhomond.

J'ai fait autant que j'ai pu le tour de ma prison, mais il y a bien des pays que je n'ai pas visités, pour des raisons accidentelles : l'Iran, par exemple, parce que l'ami qui m'y invitait est mort. Et beaucoup d'autres, pour lesquels l'occasion, au dernier moment, a manqué. J'ai toujours aimé surtout les pays frontières, ceux qui donnent sur un lointain plus sauvage encore : la Laponie suédoise et norvégienne, le Proche-Orient à l'endroit où il devient difficile d'aller plus loin, sinon par des sentiers de montagne, l'Alaska maintenant menacé... [...] Toute ma vie, j'ai été très sollicitée par le voyage [...]. (Yourcenar 1980: 324)

Así que es un deseo de viaje carnal lo que experimenta, mejor que el apego a una tierra chica de la que la habían apartado unas circunstancias históricas contrarias. Por cierto, conoce al principio de su estancia y experiencia americana los sentimientos acostumbrados de los desterrados: un sentir bastante cercano a una toma de conciencia de desterrada. Por otra parte, reconoce que: “À ce moment-là, j'avais la nostalgie de l'Europe, ou de l'Asie, ou au moins du Mexique. Enfin, je voulais quitter les États-Unis parce que je m'y sentais dépaysée, et il m'a été parfois très dur d'y gagner ma vie" (Yourcenar 1980: 123-124).

Igualmente, en una carta personal a Jean Ballard, dice: "Durant ces années passées à distance, dans cette espèce d'Arche que furent les États-Unis, le plus affreux était ce sentiment de flotter au milieu d'un monde disparu, submergé, désormais sans terre ferme" (Yourcenar 1995: 74).

Malestar, impresión de estar separada de todo, desarraigada, en el sentido etimológico de la palabra, nostalgia de lo perdido, son sentimientos característicos de cualquier desterrado, pero no dominan en Yourcenar. Muy pronto se le impone la idea de que le corresponde lógicamente buscar y encontrar un refugio, lejos del alboroto y de la confusión de la sociedad americana. Será la casa de Petite Plaisance, en esa isla apartada del estado de Nueva York, fuera del la caos de la capital. Lo dice sin rodeos: "Alors je suis restée aux Etats-Unis. Il faut bien être quelque part..." (Yourcenar 1980: 129).

Consigue la nacionalidad americana en 1949. Sin embargo, indica claramente en una carta que escribe a uno de sus lectores: 'J'ai vécu dans tant de pays que j'ai 
peine à me croire, par moments, d'une nationalité quelconque" (Yourcenar 1995: 111).

Más que una desterrada en el sentido tradicional del vocablo, Yourcenar ha sido, voluntaria, lúcida, orgullosamente una marginada, una nómada, una " irregular" según la fórmula muy acertada de Josyane Savigneau en Le Monde (1994).

Es cierto que Yourcenar ha conocido muy a menudo la voluptuosidad y la emoción de los regresos, como le pasó en 1954-1955 con su vuelta al Mont-Noir.

Después de un largo período de inmovilidad forzada por culpa de la enfermedad de Grace Frick, y más aún a raíz de la muerte de su amiga en 1979, su vida no es más que una sucesión de idas y venidas por el mundo entero. En los años 80 seguirá con el mismo ritmo al lado de su nuevo y último amor, el fotógrafo Jerry Wilson.

Yourcenar no fue nunca una proscrita como lo fue Madame de Staël. Su condición material, social y moral no se asemeja en ningún momento a la de un Victor Hugo, apartado e incomunicado en Guernesey, quien grita su enfado y su desesperación de poeta-patriota que se levanta solo contra la tiranía de Napoleón.

No se ve en ella la amargura, el tono vengador y la maldición que se desprenden de los escritos de esos famosos desterrados. Tampoco la tonalidad nostálgica que asoma en numerosos poetas españoles exiliados, como Rafael Alberti en Italia o León Felipe en Méjico, ni el pesimismo que invade los textos de los intelectuales alemanes que huyeron del Tercer Reich. En Yourcenar, ningún sentimiento romántico del destierro de un Lamartine que exalta a lo largo de poemas o de textos el recuerdo idealizado del territorio natal. Tampoco la puesta en duda de su patria y de sus valores tradicionales de un Juan Goytisolo que reniega finalmente de sus raíces.

Yourcenar no escoge como Ulises las pruebas del regreso para tratar de reconstituir una identidad auténtica que hubiera perdido. En la medida en que su vida es un continuo ir y venir, no experimenta la necesidad de cantar el regreso. A decir verdad, Yourcenar no es una figura de desterrada en el sentido estricto de la palabra. Sufre una necesidad moral más que una prohibición. No está desterrada, tampoco expulsada o deportada.

Cuando sube al barco Mauritania en mayo de 1951 rumbo a Europa, para su primer regreso después de la guerra, no se trata del retorno de una desterrada sino del final de una separación, dolorosa por cierto, pero no traumática. Más que hacia una tierra perdida, regresa hacia una cultura, unos amigos, unos editores.

Este destierro no ha sido ni será injusto o glorioso u honorable, como tal. Es un avatar como otros, voluntarios en su mayoría, de su biografía. Yourcenar no es, o lo es muy poco, la mujer de un "doble país" en el sentido en que lo emplea el escritor libanés Salah Stétié. Entre su patria de origen y su patria de adopción adopta una actitud oblicua, no sirve (salvo para los spirituals negros) de puente, no es ni quiere ser un mediador.

Sí, irregular más que clásica, universal más que apegada a una tierra singular, preocupada por la voluntad de dar la vuelta al mundo incansablemente, hasta sus últimos días, mejor que volver a encontrar su espacio original, por lo demás muy variado y complejo.

Examinemos ahora el caso de la novela El denario del sueño que puede ser ejemplar para entender esta relación con el destierro que tratamos de definir en Yource- 
nar $^{3}$. Según su propia cronología 4 , que presenta en el volumen de sus Euvres Romanesques (Yourcenar 1982: XVIII), pudo observar, durante una estancia en Milán y Verona en 1922, la marcha sobre Roma y fue entonces cuando tomó conciencia del peligro fascista. En los años posteriores estuvo en contacto con los intelectuales italianos exiliados, contactos que fueron el material, la base de impresiones y recuerdos que suscitan la redacción de una primera versión de la novela, durante una nueva visita a Italia y frecuentes estancias en Viena, y su publicación en $1934^{5}$.

En esa Roma imaginaria de la dictadura, Yourcenar nos presenta una amplia red de personajes: Paolo Farina, Lina Chiari, Giulo Lovisi, Giuseppa, Giovanna et Carlo Stevo, Rosalia di Credo, Miss Jones, Ruggero di Credo, Marcella Ardeati, Angiola Fidès, Alessandro Sarte, la tía Dida, el tío Cicca, Clément Roux, Oreste Marinunzi. Entendemos que Yourcenar ha podido apreciar, con esa nutrida galería de seres desesperados, solitarios y apasionados, lo que llama "[...] le suprême privilège du romancier qui est de se perdre tout entier dans ses personnages ou de se laisser posséder par eux" (Yourcenar 1982: 1028).

La relación entre ellos se da a través del traslado de una moneda que los personajes se pasan unos a otros, lo que reúne a la vez los fragmentos y esa cadena de individuos quienes, de otro modo, establecen entre sí relaciones en ese lugar único, Roma, el día en que pronuncia un discurso el dictador que suponemos es Mussolini, aunque nunca se le nombre así, cuando se organiza un atentado contra su persona.

En esa historia profundamente política, el personaje típico del desterrado es sin duda alguna el intelectual antifascista Carlos Stevo, condenado a cinco años de deportación por un tribunal especial acusado de hacer propaganda subversiva. Detenido en Roma, a su regreso de Viena, fallece en las Islas Lipari, después de redactar una última carta de retractación. Pero este personaje que podría dar lugar a un perfecto tipo de héroe desterrado no es más que una sombra, una presencia / ausencia.

Al igual que el Dictador, Stevo influye a los protagonistas de la historia, como Marcella, Massimo o Alessandro Sarte, está en el centro de sus diálogos y de sus reflexiones, de sus enfrentamientos incluso, pero no aparece nunca directamente. Es más bien la figura emblemática del intelectual torturado, atormentado y contradictorio que la encarnación heroica del proscrito. Yourcenar no analiza más en profundidad a ese personaje; sólo comenta: “Et maintenant qu'il n'était plus quelque part qu'un chiffre sur un rocher, ce Carlo, redevenu irréel, les inquiétait comme un fantôme" (Yourcenar 1982: 183) ${ }^{6}$.

Así que no se puede considerar a los demás personajes más que como desterrados dentro de sí mismos, seres a menudo extraviados o castigados por la vida,

\footnotetext{
3 De ahora en adelante nos referiremos en nuestras citas a la versión francesa publicada en el volumen Euvres romanesques (Gallimard, 1982). Para facilitar la lectura y la consulta de los lectores españoles, daremos en nota de pie de página la referencia a la edición española de El denario del sueño (Alfaguara, 1985).

4 Es totalmente inusual que el autor cuyos textos se presentan en la famosa colección Bibliothèque de la Pléiade redacte él mismo su cronología. Suele hacerlo la persona encargada de la edición. Es una prueba más, por parte de Yourcenar, de su voluntad de controlarlo todo.

5 Yourcenar publicó una segunda edición, ampliada, en 1954 y una versión teatral de la misma historia en 1961, bajo el título Rendre à César (Dar a César).

6 Yourcenar 1985: 43.
} 
que se encuentran por casualidad en Roma y se entrecruzan. Así, Roma es el lugar de encuentro de aventuras individuales arraigadas en un fuera que los marcó de una manera inolvidable y hacia el que tienden a volver. Claro que son personajes secundarios, pero en los que vamos a observar el punto de vista de la misma Yourcenar.

Tomemos primero el caso de la joven inglesa Miss Jones. Está de paso por Italia, considera este viaje como una "locura" y espera recuperar en Inglaterra su cargo de secretaria después de hacer durante algún tiempo de vendedora en la tienda de perfumes de Giulio Lovisi. Está a la espera de algo, de madrugada sale para Londres con su maleta en la mano, decepcionada por su experiencia en una ciudad a la cual ha llegado nutrida de poetas románticos. Tiene la nostalgia de los placeres cotidianos de su tierra, se va entre desilusión y decepción.

Más complejo es el personaje de la tía Dida, la vendedora de flores, vieja señora que trabaja en Roma desde hace treinta y cinco años, solitaria, originaria de Ponte Porzio, perdida entre tierra y cielo. Su hijo Nanni se ha ido a Argentina, el otro, Ilario, es hortelano cerca de Roma; su hija Agnese vive en Florencia. Instalada a la entrada del palacio Conti, cerca del cine Mondo, sobrevivió a un rey, a tres papas y a dos maridos. El café Impero es su refugio, su isla en esta ciudad implacable. Como la iglesia es el refugio del tío Cicca, párroco de Santa María la Menor desde hace treinta años.

Esos pobres individuos parecen haber encontrado un espacio de paz en medio de tantos dramas que estallan a su alrededor y los superan. Hace treinta años que el pintor Clément Roux no ha vuelto a ver Roma:

Et voilà près de trente ans que je n'ai pas revu Rome. Changée en laid, comme toute la terre... Oh ! Je suppose qu'un type jeune, comme toi, trouve à ça une beauté tout autre que tu regretteras aussi dans trente ans. Plus du tout pour moi... J'ai horreur du bruit... Je déteste la foule... Mais ce soir, tout de même, je n'ai plus tenir dans leurs salons du César Palace... Et à pied, tout seul, je suis allé... (Yourcenar 1982: 264) ${ }^{7}$

Está perdido en esta ciudad, corre detrás de sus recuerdos y de sus sensaciones. Escéptico, no cree en la política y afirma: "Et puis, tu sais, moi, la politique... D'ailleurs je ne suis pas d'ici... Pourvu seulement qu'il ne nous amène pas la guerre" (Yourcenar 1982: 267) ${ }^{8}$.

Clément Roux pronuncia una frase clave para entender la actitud de Yourcenar frente al destino. Dice a Massimo: "Tu es français ? Non, russe. Je connais l'accent. Moi, je suis d'Hazebrouck. Parce qu'il faut bien être de quelque part..." (Yourcenar 1982: 265$)^{9}$.

Recordamos que Yourcenar ha empleado la misma expresión a propósito de sí misma en su entrevista con Matthieu Galey. Como su interlocutor, al que encuen-

\footnotetext{
${ }^{7}$ Ibíd.: 154 .

${ }^{8}$ Ibíd.: 158 .

${ }^{9}$ Ibíd.: 155 .
} 
tra en las calles de Roma, el ambiguo ruso Massimo que va a reunirse con su madre, anticuaria en Viena: él también está solamente de paso antes de una nueva salida.

Ils me jugeront incompétent ou complice. Et, en ma qualité d'étranger, ils me prieront de quitter leur belle Italie, et de faire estampiller ailleurs mon passeport Nansen... Encore mon ignoble chance... Tout va se réduire à un séjour chez ma mère qui est antiquaire à Vienne. (Yourcenar 1982: 266) ${ }^{10}$

Y abandona en su pisito de la calle San Niccolo da Tolentino los pocos libros que componían su biblioteca: un Chestov, un Berdiaeff, un Kierkegaard, un Apollinaire, y lleva consigo solamente dos volúmenes de su amigo Carlos Stevo. Confirma de este modo lo que había contestado a Marcella al final de su entrevista de despedida, cuando ella le preguntó a dónde se iba: "Une seconde, il hésita. Elle espéra qu'il proposerait de la suivre et qu'elle aurait à l'en empêcher. Mais au contraire: 'Nulle part, comme d'habitude"' (Yourcenar 1982: 236) ${ }^{11}$.

Quizás sea la encargada de los cirios Rosalia di Credo la que parece participar más del destierro a la vez espacial e interior, ya que desde su primera aparición en el relato se la presenta como "Si Giulio n'avait pas été assourdi par le bourdonnement de ses propres maux, cette simple phrase lui eût fait reconnaître en Rosalia une déportée du bonheur" (Yourcenar 1982: 183)12.

El historial de su familia es una sucesión de rupturas desgarradoras: su padre, Ruggero, oriundo de Sicilia, ha sido cónsul en Biskra, en Argelia; casado con una judía argelina y jubilado, regresa a su casa de Gemara en Sicilia. Es un personaje extraño, a la vez zahorí y arqueólogo: “[...] il devenait éloquent quand il s’agissait de Gemara" (Yourcenar 1982: 194) ${ }^{13}$.

Al tener que dejar su finca en circunstancias dramáticas por culpa de un motín de los campesinos, se vuelve loco y acaba en un manicomio, únicamemente obsesionado por su pasado: "Au moment de sombrer, Don Ruggero regagnait son île : la folie, c'était sa Sicile” (Yourcenar 1982: 203$)^{14}$.

Rosalia sufre dos choques sucesivos: la salida forzada de Sicilia y la de su hermana Angiola, que se marcha a una pensión de Florencia. Entonces se apunta que "[...] la vie de Rosalia se partageait entre l'attente d'un retour et celle d'un départ" (Yourcenar 1982: 199) ${ }^{15}$.

Ahora en Roma, convertida en una solterona solitaria, sueña con su infancia, en Gemara, cuando se entera de la venta por embargo de la hermosa casa de su pasado:

10 Ibíd.: 156.

11 Ibíd.: 115.

12 Ibíd.: 43. Reparemos en que el texto de Yourcenar dice: “une déportée du bonheur". La palabra francesa "déportée" es algo distinta a "exiliada", palabra adoptada por la traducción al castellano, que es más reductora o general. Deportado remite a un contexto más dramático, a un castigo, por ejemplo el de la salida forzada de los judíos hacia los campos de concentración en la Segunda Guerra Mundial.

13 Yourcenar 1985: 58.

14 Ibíd.: 70.

15 Ibíd.: 65. 
Un minotier enrichi avait le droit de jeter bas Gemara puisque ceux de la famille, s'ils y retournaient, le miroir ne les reconnaîtrait pas. Elle-même, sans le savoir, elle avait vingt fois démoli, puis rebâti ces vieux murs : le Gemara luxueux qu'elle voulait pour sa soeur, le Gemara princier qu'elle souhaitait au père pour le venger des dédains du beau monde n'avait rien de commun avec le logis de son enfance : il n'existait plus, même en elle, où des rêves adultéraient ses souvenirs. (Yourcenar 1982: 204) ${ }^{16}$

Entonces, como casi todos los demás personajes que viven en esa Roma aplastada por el Dictador y en la cual se siente tan sola, no tiene más que un deseo: morir. Para ella el colmo de la desesperación es esa maleta: "Rosalia s'assit sur sa malle qu'il ne serait plus jamais question d'expédier nulle part, penchée sur le réchaud qu'elle éventait à l'aide des documents du notaire"' (Yourcenar 1982: 205).

Su hermana Angiola, atrapada también en una vida agitada, vuelve a su pasado. Igual que Rosalia, quien se acordaba del pan al anís, de los higos frescos, del olor a naranjas, de los almendros de Gemara, vuelve a experimentar el sabor a granadas del jardín de la casa siciliana, “...mais Angiola n’était pas femme à s'embarrasser d'une famille dérangeant l'image embellie qu'elle présentait de son passé" (Yourcenar 1982: 242).

Durante su encuentro con el doctor Alessandro Sarte, en el palco del cine Mondo, experimenta ese sentimiento extraño: "Ici, près de ce nouveau venu, elle n'aurait pu que singer l'amour. 'Italien ? De passage à Rome'. Mentir, couper les ponts entre l'autre et soi, s'enfoncer dans le mensonge comme à l'intérieur d'une île" (Yourcenar 1982: 248).

Se ve pues que a Yourcenar no le interesa tanto el destierro político, que utiliza más bien como resorte dramático, sino el más sutil, menos maniqueo, más cercano a ella, de unos pobres seres perdidos, zarandeados por las circunstancias de la vida, entre espera y salida, entre pasado y presente, agarrados por la fuerza a un "en algún sitio", camino inexorable hacia un "en ningún sitio".

No hay nada romántico o ideológico en ella, sino más bien un apego visceral a su tierra, no en un sentido patriótico de la palabra sino cósmico. Esa eterna viajera se identifica perfectamente con las figuras errantes de Clément Roux, de Massimo, de Rosalia di Credo o de Angiola. Marcella, por su parte, aislada en su camino interior, representa la Tierra y el Pueblo. Lo deja todo, y de ese destierro singular nace la decisión irracional de matar al Dictador, sacrificándose de este modo lo mismo que Rosalia, en su propia crisis, con el incendio de su casa.

Por lo tanto, la mayor desgracia se vive cuando, como Rosalia di Credo, uno se sienta en un baúl "qu'il ne serait plus jamais question d'expédier nulle part" (Yourcenar 1982: 205). En Yourcenar, la búsqueda testaruda de la cordura tiene que pasar por esas pruebas terribles que le impone al ser humano el destino, o sea la casualidad.

En definitiva, Yourcenar se asemejaría más bien, a nuestro parecer, a un Jorge Luis Borges, ese escritor cosmopolita quien, como todos los argentinos, decía que

${ }^{16}$ Ibíd.: 71. 
"sólo descendía del barco". Comparte con él la misma cultura universal, la frialdad geométrica y la voluntad del filosófo que pretende alcanzar la serenidad mediante la superación de las pasiones.

En 1986, después de la muerte de Jerry Wilson, Yourcenar viaja a Bruselas para entrevistarse con André Delvaux a propósito de la adaptación cinematográfica de L'CEuvre au noir (Opus Nigrum), y a Génova, para visitar a Borges, que vivía entonces en un hotel de esa ciudad, poco antes de morir. Yourcenar contó al diario francés La Voix du Nord ese extraordinario diálogo entre el autor de Con los ojos abiertos y el poeta ciego:

Je l'aimais beaucoup, je sens le monde plus pauvre de la mort de Borges. Il avait gardé toute sa lucidité, sa fermeté. Comme c'est étrange qu'il soit mort de façon très borgésienne, venant de louer un appartement qui n'avait pas de numéro, dans une rue qui n'avait pas de nom... Je lui ai demandé : Borges, quand est-ce que vous sortirez du labyrinthe ? Il m'a fait cette réponse : quand tout le monde en sera sorti. (La Voix du Nord 16/08/1986)

Fue entonces cuando, al regresar a la isla de Montes Desiertos, retomó la escritura de Quoi ? l'Eternité, tercer tomo de su ciclo autobiográfico Le Labyrinthe du monde. La conferencia que Yourcenar pensaba presentar en Europa durante su gira proyectada para el otoño de 1987 iba a recoger las reflexiones que vamos a leer más tarde en la publicación póstuma En pèlerin et en étranger (Yourcenar 1989).

Se puede hablar por lo tanto de una escritura del destierro en Yourcenar en la medida en que, gracias a sus numerosos textos periféricos, se sabe que escribía en una multitud de lugares repartidos sin orden ni concierto, según el capricho de sus viajes: casas de alquiler, habitaciones de hoteles, salas de espera de estación, retiradas diversas.

Yourcenar es una creadora insular en el sentido de que siempre se ha reservado espacios de libertad interior en el centro de espacios exteriores en los que se encontraba por la casualidad de sus movimientos, que en ningún momento la encerraron. Por eso decía al periodista Jacques Chancel: “Qu'est-ce qu'une île ? La table de café est une île" (Yourcenar 1999a: 49).

No se ha subrayado lo suficiente el hecho de que Yourcenar haya escogido voluntariamente vivir en medio del espacio tan amplio de Estados Unidos en una pequeña isla, la de los Montes Desiertos, muy apreciada por cierto por su tranquilidad y su entorno humano discreto:

J'ai toujours aimé les îles. J'ai aimé l'Eubée, j'ai aimé Égine, j'ai aimé Capri -qui est beaucoup moins touristique qu'on ne le dit, quand on vit dans un coin perdu. Chaque île est un petit monde en soi, un petit univers en miniature. (Yourcenar 1980: 134)

Ahí, esa isla, encontró precisamente lo que suelen regalar las islas: el repliegue sobre sí mismo, un sedentarismo protegido, la soledad; pero al mismo tiempo, de modo paradójico, una necesidad de evadirse, de salir a este horizonte fascinante que da miedo y atrae a la vez, provocando a la fuerza el deseo urgente del viaje, no como ocio turístico sino como obligación moral. 
Podemos afirmar pues que, para ella, el espacio físico en que vive es relativamente poco importante, ya que siente en su interior la obligación y la voluntad de encerrar en sí misma al universo entero que cabe en sus maletas. Su errar es estudioso, curioso, obstinado. Acompaña su escritura, la alimenta, no la funda.

Si es verdad que la experiencia, la conciencia e incluso la estrategia del destierro desempeñan un papel secundario en los textos autobiográficos de Yourcenar, en cambio, podemos ver un avance lento pero seguro del concepto de destierro en los personajes de las obras de ficción.

Así se entiende mejor ahora otra reflexión significativa de Yourcenar en una carta que envía a Christian Dumais-Lvowski en 1986: "Il n'est jamais trop tôt pour commencer à remplir des agendas, même en gardant des points d'interrogation" (Dumais-Lvowski 2002: 79).

Durante toda su existencia Yourcenar viajará, y emprenderá peregrinaciones sentimentales, intelectuales o estéticas esenciales para forjar la lenta, testaruda y controlada construcción de su obra y de su vida. Siempre buscará cómo llenar esos puntos de interrogación y procurar transformarlos en puntos rotundos, afirmados con autoridad frente a la posteridad.

\section{Bibliografía}

DELCROIX, Maurice, (coord.) (2002): Marguerite Yourcenar, portrait d'une voix. Coll. Les Cahiers de la NRF. Paris: Gallimard.

DUMAIS-LVOWSKI, Christian (2002): La promesse du seuil, un voyage avec Marguerite Yourcenar. Photographies de Saddri Derradji, coll. Archives privées. Paris: Actes Sud.

GROSLAR, Michèle (1998): Yourcenar, biographie, "Qu'il eût été fade d'être heureux ». Bruxelles: Éditions Racine / Académie Royale de Langue et de Littérature Françaises de Belgique.

ROSBO, Patrick de (1972): Entretiens radiophoniques avec Marguerite Yourcenar. Paris: Mercure de France.

SARDE, Michèle (1995): Vous, Marguerite Yourcenar. La passion et ses masques. Paris: Laffont.

SAVIGNEAU, Josyane (1990): Marguerite Yourcenar, l'invention d'une vie. Paris: Gallimard.

YOURCENAR, Marguerite (1971): Denier du rêve. Paris: Gallimard.

- (1980): Les yeux ouverts, entretiens avec Matthieu Galey. Paris: Lecenturion.

- (1982): Euvres Romanesques. Coll. Bibliothèque de la Pléiade. Paris: Gallimard.

- (1985): El denario del sueño. Traducción de Emma Calatayud. Madrid: Alfaguara.

- (1989): En pèlerin et en étranger. Paris: Gallimard.

- (1991): Le Tour de la prison. Paris: Gallimard.

- (1995): Lettres à ses amis et à quelques autres (de 1909 à 1987). Paris: Gallimard.

- (1999a): Radioscopie de Jacques Chancel. Entretiens 11-15 juin 1979, Paris: Éditions du Rocher.

- (1999b): Sources II. Coll. Les Cahiers de la NRF. Paris: Gallimard.

- (2000): Cartas a mis amigos. Madrid: Alfaguara.

- (2004): D’Hadrien à Zénon, correspondance 1951-1956. Paris: Gallimard. 
- (2007): «Une volonté sans fléchissement », correspondance 1957-1960. Paris: Gallimard.

- (2008): Con los ojos abiertos: conversaciones con Marguerite Yourcenar. Traducción de Elena Berni, col. Testimonio. Barcelona: Plataforma.

ZACCHERA, Paolo (2009): "De l'Île des Monts-Déserts au Monterosso: correspondance et rencontres avec Marguerite Yourcenar, 1979-1987", en SIEY (Société Internationale d'Etudes Yourcenariennes), bulletin n. 30, décembre 2009. 